\title{
Faktor - Faktor Yang Mempengaruhi Motivasi Karyawan Pada Industri Elektronik di Kota Batam
}

\author{
Alden Nelson \\ Universitas Internasional Batam \\ alden.nelson@uib.ac.id
}

\begin{abstract}
Abstrak
Penelitian memiliki tujuan untuk mengetahui faktor-faktor yang dapat mempengaruhi motivasi karyawan. Penelitian ini sangat penting karena dengan adanya motivasi maka karyawan tetap memiliki semangat didalam melakukan pekerjaannya dan tentunya akan berdampak bagi perkembangan perusahaan. Penelitian yang dilakukan fokus terhadap empat variabel yakni kepemimpinan (leadership), kerjasama tim (teamwork), dukungan manajemen (management support) dan motivasi karyawan (employee motivation). Target populasi penelitian dilakukan terhadap karyawan yang bekerja di industri elektronik di Kota Batam dan responden yang dipilih dalam penelitian adalah karyawan yang bekerja di lima kawasan industri yakni di Kawasan Industri Cammo, Kawasan Industri Batamindo, Kawasan Industri Tunas, Kawasan Industri Executive dan Kawasan Industri Panbil. Penelitian ini menggunakan metode deskriptif kuantitatif dengan teknik Non Probability Sampling. Untuk memperoleh data terhadap kuisoner yang diperolah maka pengolahan data dilakukan dengan menggunakan SPSS versi 24. Hasil dari pengolahan data yang diperoleh dengan melakukan uji t ditemukan bahwa variabel kepemimpinan memiliki nilai 2,734, kerjasama tim dengan nilai 4,367 dan dukungan manajemen dengan nilai 3,744. Ketiga hipotesa terbukti karena nilai t lebih besar dari pada 1,96 sehingga dapat disimpulkan bahwa (1) kepemimpinan memiliki pengaruh signifikan terhadap motivasi karyawan, (2) kerjasama tim memiliki pengaruh signifikan terhadap motivasi karyawan, (3) dukungan manajemen memiliki pengaruh signifikan terhadap motivasi karyawan.
\end{abstract}

Kata Kunci Kepemimpinan, Kerjasama Tim, Dukungan organisasi dan Motivasi Karyawan

\section{PENDAHULUAN}

Motivasi karyawan merupakan hal yang sangat penting dalam sebuah organisasi karena motivasi selalu dikaitkan dengan pencapaian tujuan baik secara individu maupun kelompok. Kita sebagai manusia atau karyawan tidak akan mampu mencapai kualitas yang baik ketika kita tidak memiliki motivasi kerja. Motivasi dianggap penting dalam organisasi karena organisasi membutuhkan para pekerjanya memiliki kinerja yang baik dalam setiap pekerjaan. Menurut Edy Sutrisno (2017), motivasi adalah suatu faktor yang mendorong seseorang untuk melakukan suatu aktivitas tertentu, oleh karena itu motivasi sering kali diartikan pula sebagai faktor pendorong perilaku seseorang. Oleh karena itu motivasi merupakan hal terpenting dalam diri mereka sebagai pekerja untuk menumbuhkan rasa percaya diri, bertanggung jawab dalam bekerja dan 
lain-lain. Motivasi kerja juga penting untuk memastikan tingkat kepercayaan pekerja lebih tinggi.

Motivasi dapat diartikan sebagai dorongan internal dan eksternal dalam diri seseorang yang diindikasikan dengan adanya; hasrat dan minat; dorongan dan kebutuhan; harapan dan cita-cita; penghargaan dan penghormatan (Uno, 2007).Motivasi penting bagi karyawan agar memiliki semangat dalam bekerja serta dapat berkontribusi dalam mencapai tujuan organisasi. Hal itu disebabkan tanpa motivasi maka kita sebagai manusia atau karyawan tidak bisa mencapai kualitas yang baik dalam kegiatan sehari-hari ditengah pekerjaan yang dilakukan. Bagi organisasi, motivasi sangat penting dan bagi para pekerja dimana organisasi menginginkan pekerjanya memiliki kinerja yang baik dalam pekerjaan yang dilakukannya. Motivasi dapat berpengaruh juga sebagai pendorong dalam perbuatan dan mengarahkan karyawan dalam mencapai tujuannya. Ketika karyawan memilili rasa lelah, penat dan stress dalam pekerjaannya maka maka melalui motivasi yang kuat akan berdampak pada munculnya semangat karyawan untuk tidak pantang menyerah dan terus mampu menyelesaikan pekerjaan. Semangat motivasi akan terus mengingatkan diri sendiri untuk bekerja mencapai tujuan yang diinginkan. Manfaat dan pentingnya motivasi yang diterapkan akan mendorong karyawan lebih positif dan produktif.

Motivasi pada suatu organisasi atau perusahaan bertujuan untuk mendorong semangat kerja para karyawan agar mau bekerja keras dengan memberikan semua kemampuan dan ketrampilan demi terwujudnya suatu organisasi. Pimpinan yang mengarahkan karyawan melalui motivasi akan menciptakan kondisi dimana karyawan merasa mendapatkan inspirasi untuk bekerja keras. Karyawan yang mempunyai motivasi tinggi sangat penting sehingga hasil-hasil kinerja yang tinggi akan dapat dicapai secara konsisten. Pimpinan akan melakukan pendekatan kepemimpinan yang mencerminkan suatu kesadaran bahwa produktivitas melalui karyawan merupakan bagian utama dan tidak dapat digantikan untuk mencapai tujuan organisasi. Motivasi akan memberikan inspirasi, dorongan, semangat kerja bagi karyawan sehingga terjalin hubungan kerja yang baik antara karyawan dan pimpinan sehingga tujuan organisasi dapat tercapai secara maksimal.

Berdasarkan hasil diskusi dengan rekan-rekan yang bekerja di bagian sumberdaya manusia di beberapa perusahaan khususnya di industri elektronik ditemukan rendahnya motivasi karyawan yang bekerja. Hal ini dapat dilihat pada pencapaian produktifitas yang belum sesuai target, kurangnya perhatian dan dukungan atasan atas hasil kerja karyawan, pendelegasian kerja yang kurang optimal dan kurangnya kordinasi antara karyawan yang satu dengan yang lain sehingga dibutuhkan kerjasama tim. Oleh karena itu perusahaan menginginkan karyawannya memiliki semangat dan lebih optimal maka perlu diperhatikan apa yang dapat membuat karyawan tetap memiliki motivasi karyawan yang tinggi.

\section{LANDASAN TEORI}

\section{Kepemimpinan}

Kepemimpinan dipahami sebagai suatu proses di mana satu atau lebih orang mempengaruhi suatu kelompok orang untuk bergerak ke arah tertentu. Kata kepemimpinan telah digunakan dalam berbagai hal dan aspek usaha manusia seperti politik, bisnis, akademisi dan kerja sosial. Pemimpin perusahaan atau organisasi juga memiliki peran sangat penting terhadap kinerja para pengikut dan atau organisasinya dengan memberikan motivasi kepada mereka. Gopal, R. dan R. G. Chowdhury ( 2014), pemimpin memegang peran sangat penting dalam kesuksesan ataupun kegagalan sebuah 
organisasi bahkan keseluruhan bangsanya. Gaya seorang pemimpin sangat berpengaruh pada perilaku karyawan dan peranannya terhadap strategi perusahaan. Hafeez et al. (2012), istilah motivasi selalu digabungkan dalam definisi kepemimpinan dan gaya kepemimpinan. Sebagian besar cendekiawan mendefinisikan pemimpin merupakan seseorang yang memotivasi pengikutnya untuk mencapai tujuan bersama. Selain itu, terdapat banyak teori dan gaya kepemimpinan, namun sektor yang berbeda atau organisasi yang berbeda mungkin memerlukan gaya kepemimpinan yang spesifik. Hal tersebut mau menyatakan bahwa agar pemimpin menjadi lebih efektif maka pemimpin harus mengetahui gaya kepemimpinan mana yang sesuai dengan kebutuhan motivasi karyawan jika tidak, efektivitasnya akan berkurang.

\section{Kerjasama Tim}

Kerjasama tim diartikan sebagai jenis kerjasama yang terjadi antara anggota kelompok yang mengerjakan suatu tugas atau penugasan. Demikian pula, kerja tim umumnya dipahami sebagai suatu kesiapan atau kemauan orang-orang dalam suatu kelompok untuk bekerja sama dan mencapai tujuan bersama (Mulika, 2010). Kemauan adalah syarat untuk menciptakan tim kerja yang nyata. Demikian pula, tujuan umum dan kinerja kolektif juga penting untuk menciptakan kerjasama tim yang dipenuhi dengan tingkat semangat kerja tim yang diperlukan. Keberadaan atribut kerja tim memberikan kepercayaan diri dari anggota tim, tingkat keamanan emosional yang tinggi, kemampuan untuk merencanakan dan membuat keputusan kolektif secara positif.

Kerjasama tim juga membantu dalam menciptakan lingkungan kerja yang sehat dan berdasarkan agenda yang adil, bermanfaat dalam hal strategi, dan tugas-tugas kreatif. Demikian pula, tidak adanya nilai dan praktek dari kerjasama tim, kekecewaan, kegagalan pekerjaan, tingkat moral karyawan yang lebih rendah dan berdampak pada rendahnya produktivitas (Oseiboakye, 2015). Kerjasama tim memungkinkan kelompok untuk memanfaatkan kecerdasan kolektif dari pada pengambilan keputusan secara individual. Keputusan kelompok dibahas dan dijelaskan oleh setiap anggota kelompok sehingga mendapat dukungan dari setiap anggota kelompok. Produktivitas dalam suatu kelompok selalu lebih besar dari pada hasil individu asalkan tim tersebut telah dibuat dengan protokol grup standar. Jika sifat pekerjaan membutuhkan model kreatif dan inovatif untuk bekerja, maka berpikir sebagai kelompok sangat relevan (Mulika. 2010). Dengan demikian, kerjasama tim selalu penting untuk organisasi jenis apa pun karena organisasi adalah aktivitas kelompok (Sanyal \& Hisam, 2018).

\section{Dukungan Organisasi}

Dukungan organisasi didefinisikan oleh Krishnan dan Mary (2012) sebagai pendapat karyawan tentang sejauh mana mereka dihargai dan diakui oleh organisasi mereka. Wann Yih dan Hatik (2011) menggambarkan dukungan organisasi yang dirasakan sebagai sudut pandang karyawan mengenai perhatian organisasi tentang upaya dan kesejahteraannya. Dukungan organisasi yang dirasakan sebagai kompensasi, penghargaan, dan kepedulian untuk kesejahteraan karyawan ( Rhoades dan Eisenberger, 2002). Karyawan percaya bahwa pemberi kerja harus menjaga kebutuhan sosial, emosional mereka dan memberikan kompensasi kepada mereka ketika mereka meningkatkan upaya mereka di tempat kerja (Krishan \& Mary, 2012). Lebih lanjut, beberapa faktor yang dikenal sebagai substitusi dari dukungan organisasi seperti penghargaan dan kompensasi, kondisi kerja dan keadilan (Baran, Shanock, \& Miller, 2012). 


\section{Motivasi Karyawan}

Motivasi karyawan merupakan aspek kritikal di tempat kerja yang mengarah pada kinerja departemen dan bahkan perusahaan. Motivasi karyawan adalah tingkat energi, komitmen, dan kreativitas yang dibawa oleh pekerja di perusahaan ke dalam pekerjaannya. Memotivasi karyawan perlu menjadi rutinitas yang teratur untuk dilakukan. Seperti yang dikatakan Wheelhouse "ada beberapa faktor yang menjadi dasar bagi kinerja pekerja dan bukan merupakan motivator yang efektif jika faktor-faktor tersebut diabaikan oleh manajer sehingga akan berdampak negatif pada motivasi".

Dalam buku perilaku organisasi: meningkatkan kinerja dan komitmen di tempat kerja (2017, 162), Colquitt, Lepine dan Wesson menyatakan bahwa "beberapa topik perilaku organisasi lebih penting bagi karyawan dan manajer daripada motivasi." Motivasi karyawan memainkan peran mendasar dalam organisasi yang menetapkan tujuan strategis untuk mencapai kinerja yang tinggi. Dari sejumlah teori motivasi yang berbeda yang telah dipelajari oleh peneliti, hierarki kebutuhan Maslow dan teori motivasi dua faktor yang dikembangkan oleh Herzberg adalah dua teori paling signifikan yang telah banyak diterapkan oleh beberapa organisasi ke dalam praktik meningkatkan motivasi karyawan.

\section{METODOLOGI PENELITIAN}

Penelitian dilakukan dengan melakukan pendekatan deskriptif kuantitatif, dimana sumber data diperoleh dari data primer dan sekunder. Teknik pengumpulan data dilakukan dengan menyebarkan kuesioner kepada responden serta melakukan wawancara, dan observasi untuk memastikan keakuratan data. Pengolahan yang dilakukan adalah dengan mengolah data yang masuk yang telah dikumpulkan dari hasil kuesioner. Pada penelitian ini menggunakan 23 estimated parameter (indikator) dan untuk mengantisipasi adanya sampel yang tidak bisa digunakan maka responden yang ditetapkan sebanyak 130 responden. Penelitian ini menggunakan teknik Non Probability Sampling dengan cara Sampling Purposive. Dimana peneliti menggunakan pertimbangan sendiri secara sengaja dalam memilih anggota populasi yang dianggap sesuai dalam memberikan informasi yang dibutuhkan untuk penelitian.

\section{Model Penelitian}

Berdasarkan penjelasan di atas maka kerangka konseptual penelitian adalah

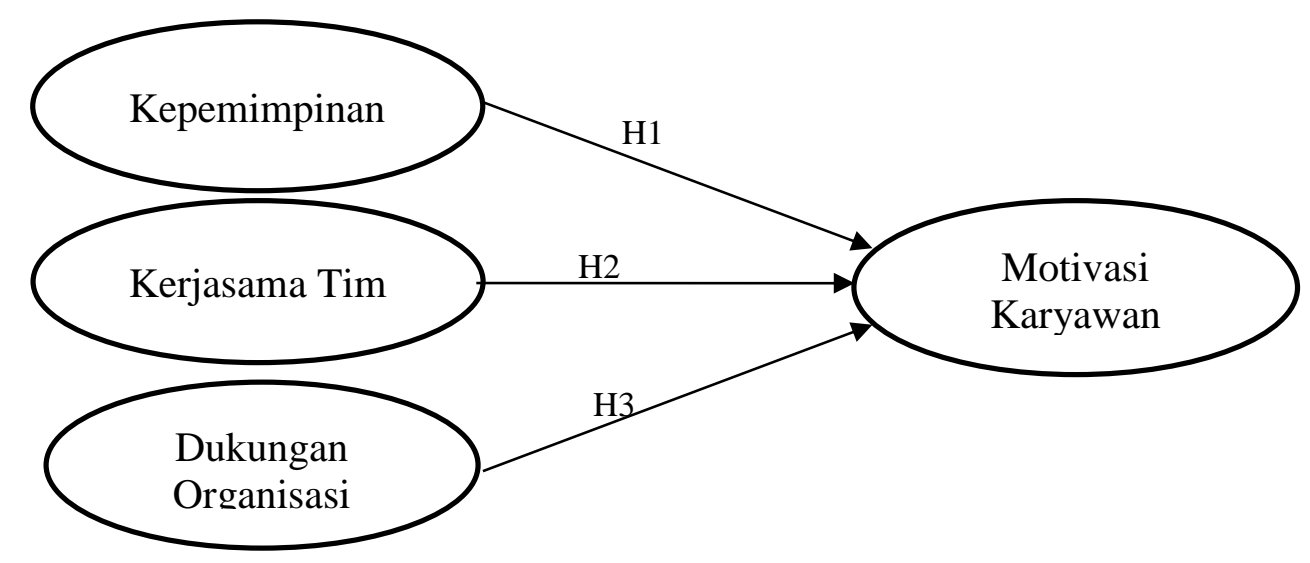

Berdasarkan penjelasan penelitian di atas maka peneliti mengilustrasikan hipotesis sebagai berikut :

H1 : Kepemimpinan berpengaruh positif terhadap motivasi karyawan 
H2 : Kerjasama tim berpengaruh positif terhadap motivasi karyawan

H3 : Dukungan organisasi berpengaruh positif terhadap motivasi karyawan

\section{HASIL PENELITIAN}

\section{Uji Validitas dan Uji Reliabilitas}

Berdasarkan hipotesa diatas maka dapat dijelaskan bahwa terdapat 3 variabel independen yang terdiri dari 4 indikator untuk variabel kepemimpinan, 11 indikator untuk variabel kerjasama tim dan 5 indikator untuk variabel dukungan manajemen serta 1 variabel dependen motivasi karyawan yang terdiri dari 3 indikator.

Setelah dilakukan pengujian data terhadap uji validitas dan reliabilitas maka indikator akan dinyatakan valid jika memiliki nilai outer loading > 0.5 (Ghozali, 2011) dan dinyatakan reliabel jika variabel menunjukkan nilai composite reliability $>0.7$ (Chin, 1998 dan Hair et al., 2011). Hasil uji validitas yang sudah dilakukan terdapat 1 indikator yang tidak valid dari 23 indikator yang ada karena nilainya dibawah 0.5 terdapat dalam tabel 4.1 dan untuk hasil uji reliabilitas ditemukan bahwa semua variabel baik independen dan dependen adalah reliabel dan dapat dilihat dalam table 4.2.

Tabel 4.1

Hasil Uji Validitas

\begin{tabular}{lcc}
\hline \multicolumn{1}{c}{ Variable } & Loading factor & Kesimpulan \\
\hline Kepemimpinan 1 & 0,612 & Valid \\
Kepemimpinan 2 & 0,577 & Valid \\
Kepemimpinan 3 & 0,620 & Valid \\
Kepemimpinan 4 & 0,695 & Valid \\
Kerjasama Tim 1 & 0,699 & Valid \\
Kerjasama Tim 2 & 0,738 & Valid \\
Kerjasama Tim 3 & 0,782 & Valid \\
Kerjasama Tim 4 & 0,780 & Valid \\
Kerjasama Tim 5 & 0,817 & Valid \\
Kerjasama Tim 6 & 0,813 & Valid \\
Kerjasama Tim 7 & 0,767 & Valid \\
Kerjasama Tim 8 & 0,817 & Valid \\
Kerjasama Tim 9 & 0,735 & Valid \\
Kerjasama Tim 10 & 0,756 & Valid \\
Kerjasama Tim 11 & $-0,480$ & Tidak Valid \\
Dukungan Manajemen 1 & 0,728 & Valid \\
Dukungan Manajemen 2 & 0,685 & Valid \\
Dukungan Manajemen 3 & 0,740 & Valid \\
Dukungan Manajemen 4 & 0,841 & Valid \\
Dukungan Manajemen 5 & 0,796 & Valid \\
Motivasi Karyawan 1 & 0,747 & Valid \\
Motivasi Karyawan 2 & 0,742 & Valid \\
Motivasi Karyawan 3 & 0,799 & Valid \\
\hline
\end{tabular}

Sumber: Data Primer diolah (2021) 
Tabel 4.2

Hasil Uji Reliabilitas

\begin{tabular}{lcl}
\hline \multicolumn{1}{c}{ Variable } & Cronbach's Alpha & Kesimpulan \\
\hline Kepemimpinan & 0,847 & Reliabel \\
Kerjasama Tim & 0,878 & Reliabel \\
Dukungan Manajemen & 0,900 & Reliabel \\
Motivasi Karyawan & 0,857 & Reliabel \\
\hline
\end{tabular}

Sumber: Data Primer diolah (2021)

\section{Uji Linearitas}

Hasil uji linearitas pada pada gambar 4.1 diatas, jelas bahwa grafik normal plot variabel yang dipengaruhi atau dependen variabel motivasi karyawan menyajikan informasi mengenai distribusi normal. Mengamati cara penyebaran data dimana mulai dari bawah sampai ke atas selalu mengikuti garis diagonal. Gambaran ini merupakan bukti bahwa motivasi karyawan mempunyai distribusi yang normal.

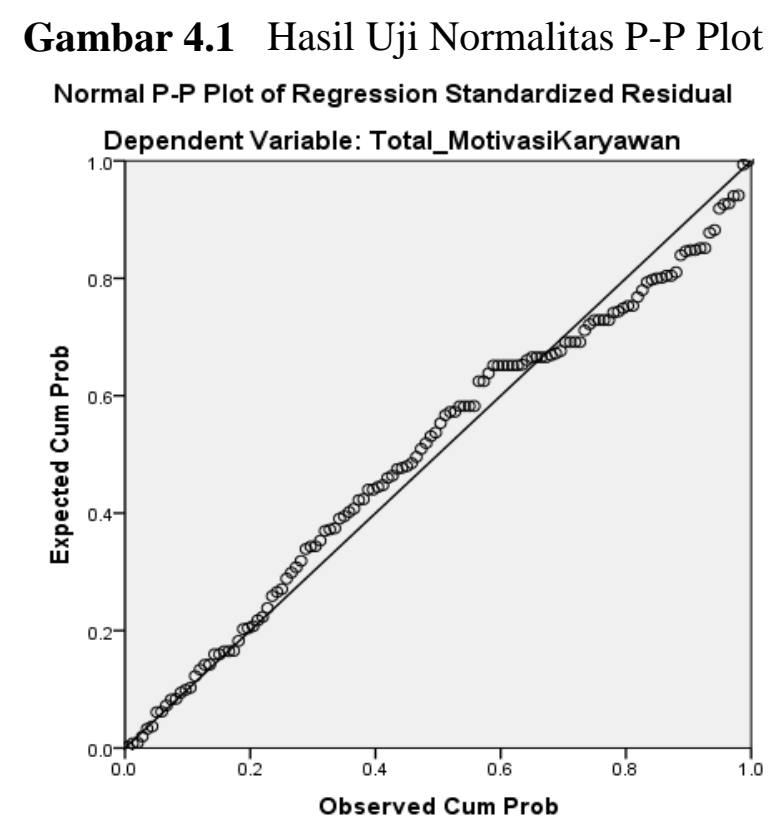

\section{Koefesien Determinasi}

Secara keseluruhan, model regresi menghasilkan goodness of fit (koefisien determinasi yang tinggi, yaitu $65.1 \%$ sesuai tabel 4.3. Hal ini menunjukkan bahwa terjadi hubungan atau korelasi antara variabel independent dan variabel dependen.

Tabel 4.3

Hasil Uji Koefisian Determinasi $\left(\mathrm{R}^{2}\right)$

\begin{tabular}{|c|c|c|c|c|c|}
\hline Model & $\mathrm{R}$ & R Square & Adjusted R Square & Std. Error of the Estimate & Durbin-Watson \\
\hline 1 & $.807^{a}$ & 0,651 & 0,643 & 1,24292 & 1,858 \\
\hline
\end{tabular}

Sumber: Data Primer diolah (2021) 


\section{Hasil Uji Hipotesis}

Berdasarkan uji t pada table 4,4, kepemimpinan, kerjasama tim dan dukungan manajemen berpengaruh positif dan signifikan terhadap motivasasi karyawan.

Tabel 4.4

Hasil Uji t

\begin{tabular}{lcccccc}
\hline \multirow{1}{*}{ Variabel } & \multicolumn{2}{c}{$\begin{array}{c}\text { Unstandardized } \\
\text { Coefficients }\end{array}$} & $\begin{array}{c}\text { Standardized } \\
\text { Coefficients }\end{array}$ & t & Sig. \\
& B & Std. Error & Beta & & \\
\hline Kepemimpinan & 0,167 & 0,061 & 0,191 & 2,734 & 0,007 \\
KerjasamaTim & 0,137 & 0,031 & 0,380 & 4,367 & 0,000 \\
DukunganManajemen & 0,229 & 0,061 & 0,329 & 3,744 & 0,000 \\
\hline
\end{tabular}

Sumber: Data Primer diolah (2021)

Hasil data yang ada sesuai dengan tabel 4.4 menunjukkan bahwa nilai $T$-Statistics dan $P$-Values dari kepemimpinan terhadap motivasi karyawan memiliki nilai sebesar 2.734 dan 0.001 . Hasil data tersebut mengartikan bahwa variabel kepemimpinan tersebut berpengaruh signifikan terhadap motivasi karyawan. Hasil pengujian ini sesuai dengan hasil penelitian sebelumnya yang dilakukan oleh Sougui et al. (2017), Njambi (2014) dan dan Mehrzi and Singh (2017).

Hasil data yang ada sesuai dengan tabel 4.4 menunjukkan bahwa nilai T-Statistics dan P-Values dari kerjasama tim terhadap motivasi karyawan memiliki nilai sebesar 4.367 dan 0.000 . Hasil data tersebut mengartikan bahwa variabel kerjasama tim tersebut berpengaruh signifikan terhadap motivasi karyawan. Hasil pengujian ini sesuai dengan hasil penelitian sebelumnya yang dilakukan oleh Ugaddan dan Park (2017), Mehrzi dan Singh (2017) dan Abbas dan Nawaz (2019)

Hasil data yang ada sesuai dengan tabel 4.4 menunjukkan bahwa nilai $T$-Statistics dan $P$-Values dari dukungan manajemen terhadap motivasi karyawan memiliki nilai sebesar 4.367 dan 0.000. Hasil data tersebut mengartikan bahwa variabel dukungan manajemen tersebut berpengaruh signifikan terhadap motivasi karyawan. Hasil pengujian ini sesuai dengan hasil penelitian sebelumnya yang dilakukan oleh Imtiaz et al. (2018) dan dan Mehrzi and Singh (2017).

\section{KESIMPULAN}

Dari hasil penelitian yang dilakukan ditemukan bahwa ketiga hipotesa tersebut terbukti sehingga disimpulkan bahwa faktor-faktor yang mempengaruhi motivasi karyawan pada industri elektronik adalah kepemimpinan, kerjasama tim dan dukungan manajemen. Hasil penelitian tersebut sesuai dengan hasil penelitian terdahulu sehingga ketika organisasi ingin agar karyawannya tetap memiliki motivasi yang tinggi maka perlu memperhatikan variabel-variabel tersebut tetapi ketika faktor-faktor tersebut tidak diperhatikan maka motivasi karyawan hilang atau turun dan berdampak pada kelangsungan organisasi.

\section{UCAPAN TERIMA KASIH}

Penelitian ini dapat dilaksanakan secara lancar karena berkat bantuan dari berbagai pihak. Ucapan terima kasih kami sampaikan kepada Universitas Internasional Batam (UIB) dan rekan-rekan bagian sumberdaya manusia yang membantu dan berpartisipasi dalam 
kuisioner sehingga kuisioner tersebut dapat digunakan untuk pengolahan data dalam pelaksanaan dan penulisan serta pembiayaan penelitian ini.

\section{DAFTAR PUSTAKA}

AA. Anwar Prabu Mangkunegara. 2016. Manajemen Sumber Daya Manusia Perusahaan. Bandung : PT. Remaja Rosda Karya.

Abbas \& Nawaz (2019) : Linking Employee Motivation with teamwork-Spirit: The Influence of Social Skill And Self Confidence. Journal of Research, Volume 35, Issue 2, Dec, 2019.

A. Khan et al. (2017) : Factors Affecting Employee Motivation Towards Employee Performance: A Study on Banking Industry of Pakistan, Published in: Proceedings of the Eleventh International Conference on Management Science and Engineering Management, Vol. 1, No. 11 (29 July 2017): pp. 615-625.

Agada. J. A, 2014, Leadership Style, Motivation and Delegation in one Selected Tertiary Institution in Kogi State, Nigeria, International Journal of Public Administration and Management Research (IJPAMR), Vol. 2, No 4, ISSN: 2350-2231, pp. 3337.

Edy Sutrisno. (2017). Manajemen Sumber Daya Manusia. Jakarta : Kencana

Grace et al. (2020): The effect of work motivation on employee performance: Empirical evidence from 4-star hotels in Mongolia, Journal of Human Resources in Hospitality \& Tourism, DOI: 10.1080/15332845.2020.1763766

Imtiaz et al. (2018)." Impact of Perceived Organizational Support on Job Satisfaction with Mediating Role of Employee Motivation: Evidence from Pharmaceutical Sector of Lahore, Pakistan". IBT Journal of Business Studies Volume 14(2), 1632, 2018.

Joshua D. Jensen (2018).” Employee Motivation: A Leadership Imperative. International Journal of Business Administration, Vol. 9, No. 2; 2018

Lee, M. T., \& Raschke, R. L. (2016). Understanding employee motivation and organizational performance: Arguments for a set-theoretic approach. Journal of Innovation \& Knowledge, 1(3), 162-169. doi:10.1016/j.jik.2016.01.004

Maryam, T. A. (2014). Employee motivation: The key to effectiveness organizational management in Nigeria. IOSR Journal of Business and Management, 16, 4 (1), 18.

Maartje PAAIS, Jozef R. PATTIRUHU. (2020). Effect of Motivation, Leadership, and Organizational Culture on Satisfaction and Employee Performance, Journal of Asian Finance, Economics and Business Vol 7 No 8 (2020) 577-588. 
Nada Al Mehrzi, Sanjay Kumar Singh, (2016) "Competing through employee engagement: a proposed framework", International Journal of Productivity and Performance Management, Vol. 65 Issue: 6, pp.831-843, https://doi.org/10.1108/IJPPM-02-2016-0037

Ni Luh et al. (2020). Faktor-faktor yang mempengaruhi motivasi kerja karyawan Koperasi Pasar Kumbangsari Bandung. Open Journal Systems, Vol.14 No.11.

Oseiboakye, E. (2015). Research on the Impact of Teamwork on Employee Performance. University of Ghana.

Park, S.M., \& Ugaddan, R.G. (2017). Quality of leadership and public service motivation: A social exchange perspective on employee engagement. International Journal of Public Sector Management, Vol. 30 Issue: 3, pp.270-285.

Robescu, O., \& Iancu, A. G. (2016). The effects of motivation on employees performance in organizations. Valahian Journal of Economic Studies, 7(2), 49-56. doi:10.1515/vjes-2016-0006

Sougui et al. (2017). "The Impact of Leadership on Employee Motivation in Malaysian Telecommunication Sector", Galore International Journal of Applied Sciences and Humanities Vol.1; Issue: 1; Jan.-March 2017. 